\title{
Psychological essentialist reasoning and perspective taking during reading: A donkey is not a zebra, but a plate can be a clock
}

\author{
Steven Frisson • Mary Wakefield
}

Published online: 27 October 2011

(C) Psychonomic Society, Inc. 2011

\begin{abstract}
In an eyetracking study, we examined whether readers use psychological essentialist reasoning and perspective taking online. Stories were presented in which an animal or an artifact was transformed into another animal (e.g., a donkey into a zebra) or artifact (e.g., a plate into a clock). According to psychological essentialism, the essence of the animal did not change in these stories, while the transformed artifact would be thought to have changed categories. We found evidence that readers use this kind of reasoning online: When reference was made to the transformed animal, the nontransformed term ("donkey") was preferred, but the opposite held for the transformed artifact ("clock" was read faster than "plate"). The immediacy of the effect suggests that this kind of reasoning is employed automatically. Perspective taking was examined within the same stories by the introduction of a novel story character. This character, who was naive about the transformation, commented on the transformed animal or artifact. If the reader were to take this character's perspective immediately and exclusively for reference solving, then only the transformed term ("zebra" or "clock") would be felicitous. However, the results suggested that while this character's perspective could be taken into account, it seems difficult to completely discard one's own perspective at the same time.
\end{abstract}

Keywords Eye movements · Psycholinguistics · Reading · Reasoning $\cdot$ Pragmatics

From the BBC News Service:

After the zebras at a zoo in the Middle East died, the owner "decided to dye two donkeys so they look like

S. Frisson $(\bowtie) \cdot$ M. Wakefield

School of Psychology, University of Birmingham,

Edgbaston,

Birmingham B15 2TT, UK

e-mail: s.frisson@bham.ac.uk zebras. [He] said he'd used masking tape and black hair dye, to disguise the white females. . . . The children don't know, so they call them zebras and they are happy to see something new."

http://news.bbc.co.uk/cbbcnews/hi/newsid_8290000/ newsid_8298600/8298658.stm

(retrieved 12 October 2009)

While syntax helps us understand who did what to whom, we also need to understand who is who and what is what. In most cases, establishing reference involves a relatively straightforward one-to-one mapping relation between a word's sense (term) and its reference (Frege, 1892/1952). However, this mapping relation is not always that simple, and different types of mappings can cause misunderstandings and, at a behavioral level, distinct processing patterns. In one-to-many mappings, one term is used to refer to different referents. This is evident for such lexically ambiguous words as pitcher (e.g., Rayner \& Duffy, 1986) and for words that become referentially ambiguous in context (e.g., "the girl" when two girls have been introduced in the story; e.g., Van Berkum, Brown, \& Hagoort, 1999). Data from eyetracking and ERP experiments suggest that one-to-many mappings can be costly and can lead to different activation patterns, but also that people are good at updating this information on the basis of the discourse context (e.g., Nieuwland, Otten, \& Van Berkum, 2007).

Many-to-one mappings, in which different terms refer to the same referent (cf. the use of both "evening star" and "morning star" to refer to the planet Venus, or the use of the terms "donkey" and "zebra" to refer to the same animal in the example above), have not been systematically studied. In the experiment described below, many-to-one mappings can come about by the application of psychological essentialist (PE) reasoning ("How would I classify this animal?") and/or perspective taking ("How would someone else classify this animal?"). 


\section{Psychological essentialism}

Imagine someone painting a donkey white with black stripes, so that it looks just like a zebra. Asked what kind of animal it really is, more than likely you will respond that it is still a donkey, even if it doesn't look like one anymore. Children less than 4 years old are more likely to classify the animal as a zebra (Keil, 1989). The reason why adults are reluctant to accept this kind of transformation into another animal is because we have certain ideas or beliefs about what makes something a member of a category. For natural kinds, we believe that they possess a certain innate, underlying essence, which is unchangeable (something akin to its DNA, even if we don't know exactly what that essence is; Gelman \& Wellman, 1991; Medin \& Ortony, 1989). This essence is critical for category membership ("Is it a donkey or a zebra?"), as well as being the cause for certain "surface features" (e.g., the fact that a kangaroo raised by goats will still have a pouch and be good at hopping; Gelman \& Wellman, 1991). As young children tend to rely more on superficial features in their classification, though without being true phenomalists (Gelman \& Markman, 1986; Gelman \& Wellman, 1991), they are more willing to accept the transformation from a donkey into a zebra (Keil, 1989).

For the classification of artifacts, the picture changes. If we have a dining plate, drill a hole in it and attach a clock face, then we are most likely to say that this transformed object has now become a clock. Similarly, if we have a coin, melt it, and turn it into a key, we are reluctant to categorize this object as being still a coin (for examples, see Keil, 1989). Artifacts are not thought to possess a psychological essence. While it has been proposed that an artifact's essence is, in effect, its function (e.g., Ahn et al., 2001; Gelman \& Bloom, 2000; Matan \& Carey, 2007; Rips, 1989) or its maker's intention (Bloom, 1996), Sloman and Malt (2003; Malt \& Sloman, 2007a, 2007b) argued that these accounts cannot explain the data, and they instead proposed a view in which the boundaries of artifact categories are not stable (see also Hampton, Estes, \& Simmons, 2007; Hampton, Storms, Simmons, \& Heussen, 2009). According to Sloman and Malt, how artifacts are categorized is largely dependent on the task at hand and the communicative goals of the situation. We will return to this issue below.

Research into psychological essentialism has been exciting and extensive (for some overviews, see Ahn et al., 2001; Gelman, 2003, 2004; Murphy, 2002; Rakison \& Oates, 2003; for a critique, see Strevens, 2000), with the idea of essentialism explored in a variety of ways and in a range of different domains (e.g., Evans, 2001; Haslam \& Ernst, 2002). While modifications to the original theory have been proposed (e.g., Hampton et al., 2007; Hampton et al., 2009; and Malt, 1994, have questioned whether people indeed always think of essences as being unchangeable), and while it is unclear whether adults always use strict essentialist categorization in all tasks (Hampton et al., 2007), it is generally assumed that, at least for natural kinds, some kind of essentialist reasoning is involved in categorization.

Most of this research, however, is "explicit" and/or offline - that is, more or less explicit questions about category membership are asked ("Is this animal a donkey or a zebra?" "Can you arrange these pictures in different categories?" "If the animal has babies, will they look like a donkey or a zebra?"), and a measurement is taken of the answer or classification. Furthermore, most research has concentrated on children's reasoning skills. While this has provided us with important insights into how people apply essentialist beliefs and from what age they do so, there are certain limitations as well. First, as explained in detail by Malt and Sloman (2007a), ${ }^{1}$ the extent to which these tasks reflect everyday reasoning is often unclear. For example, outside of the laboratory, one is unlikely to have to explicitly choose between two possible names for an object or to judge how appropriate a certain name is. Second, different tasks, and even the same task, can lead to different results. For example, in name appropriateness judgment tasks using artifacts, some evidence has pointed to the object's form being more important (e.g., Gentner, 1978), especially when the respondents are younger (Landau, Smith, \& Jones, 1998), while other evidence has suggested that the function is more significant (e.g., Rips, 1989). In contrast, using a free-naming task, Sloman, Malt, and Fridman (2001) did not observe a clear preference for using an object's form or function as the basis for its name. This lack of a preference might reflect the strong correlation between an object's form and its function, with the form affording the function (see also Kemler Nelson, Frankenfield, Morris, \& Blair, 2000). Third, offline tasks do not provide a good estimate of the speed at which categorization happens. It has been suggested (e.g., McRae, 2005; Sloman, 1996; see Kahneman, 2003, for a discussion) that while categorization on the basis of similarity is fast, categorization on the basis of naïve theories is deliberate and slow. However, some evidence has suggested that explicit theory-based categorizations can be made relatively quickly (Lin \& Murphy, 1997; Luhmann, Ahn, \& Palmeri, 2006; Palmeri \& Blalock, 2000). For example, Luhmann et al. found that participants started using causal information, which is related to theory-based categorization, when a stimulus was presented for $500 \mathrm{~ms}$ with a maximum response time of $300 \mathrm{~ms}$. This result suggests that theorybased reasoning can be employed relatively quickly (though, in terms of online processing times, this is not remarkably quick), at least when participants have to make an explicit decision under time pressure.

\footnotetext{
${ }^{1}$ While Malt and Sloman (2007a) concentrated on artifact categorization, many of the same arguments can be made concerning natural kind categorization.
} 
Whether adults can use essentialist reasoning automatically in a task that does not require an explicit evaluation of a word's reference remains an open question. We address this question by examining the reading patterns of participants while they read stories containing referring expressions that either did or did not coincide with an essentialist interpretation. In contrast to the unnaturalness of explicit categorization tasks, reading a story and understanding what the writer or narrator is referring to is a straightforward exercise. In addition, since the task was simply to read and understand the text and the participants were not asked to make any categorization judgments, the chance of task effects was minimal. Lastly, reading time measures provide an account of online processing and can indicate whether readers have categorized a referent in a certain way and how quickly they can use this information.

In the eyetracking experiment below, we used natural kind (animal) and artifact terms in transformation stories (inspired by Keil, 1989). Participants read about a donkey being turned into a zebra, or a plate into a clock, and instead of asking how appropriate they found the word that was used to refer to the animal or artifact, we looked at eye movement patterns (fixation durations, regressions, etc.). The underlying idea was that if the writer/narrator used a term that did not agree with how the reader had classified the animal or object, extra processing effort, possibly expressing surprise, would result. By looking at the conditions in which this extra effort was found, we could deduce how the reader had classified the referent and whether an essentialist classification was used. By looking at whether the effect showed up in "early" eyetracking measures (e.g., first-pass durations; see below), which arguably capture immediate processing, or in "later" measures (e.g., second-pass durations), which capture more deliberate and in-depth processing (e.g., Clifton, Staub, \& Rayner, 2007), we could estimate the degree to which the classification was done automatically. As an example, if one reads about a donkey being painted white with black stripes so that it looks like a zebra, and if one thinks that this procedure does not change the essence of the donkey, the correct term to refer to this animal would be "donkey." Hence, if one reads that the donkey was put in the field, this would coincide with how the reader has classified the animal and should cause no problems. In contrast, if the narrator mentions that the zebra was put in the field, this would clash with the essentialist classification, resulting in processing difficulties. However, this pattern would only be expected if readers indeed employed essentialist reasoning. If they instead relied on a phenomalist kind of reasoning that is, a classification based solely on external featuresthen one would expect the opposite pattern, since the animal, for the reader, now "really" was a zebra. Finally, the reader might also believe that both classifications are acceptable, in which case no differences would be expected between the use of the terms. Ultimately, one can consider this as a kind of many-to-one mapping, since there are different possible terms for the same referent, and the felicity of a particular term would depend on the reader's classification.

If we take the inanimate object cases-for instance, a plate turned into a clock - then both the essentialist view and the phenomalist view would predict that readers would accept the transformation - that is, that they would now classify the object as a clock rather than a plate. We would therefore expect that if the writer/narrator refers to the object with the term for the transformation, it would be easier to process than when the original term was used; that is, it would be easier to read that, after the transformation, the clock rather than the plate was hung on the wall.

\section{Perspective taking}

In the situation described above, the main goal was to find out how readers interpreted the natural kind and artifact terms from their own perspective. In the same experiment, we also examined how easy or difficult it would be to adopt the perspective of a story's character who was naïve with regard to the transformation.

Perspective taking has been studied largely independently in two different fields: theory-of-mind reasoning and text processing. First, in the field of theory-of-mind reasoning (for overviews, see Apperly, 2011; Doherty, 2008), some recent studies have looked at perspective taking in normal adult populations using communication games in which, for example, one has to figure out which object, out of an array of similar objects, someone is referring to. The results have not been unequivocal and seem, to a degree, to depend on the task and participants used. In a series of experiments, Keysar and colleagues (Epley, Keysar, et al., 2004; Epley, Morewedge, et al., 2004; Keysar, Barr, Balin, \& Brauner, 2000; Keysar, Lin, \& Barr, 2003; see also Horton \& Keysar, 1995) found that participants exhibited an egocentric tendency, in that they evaluated information first according to their own perspective, before correcting this interpretation when it was inappropriate. This correction happened faster and more effectively in adults than in children (Epley, Morewedge, et al., 2004), and the egocentric tendency was found in Western (American) participants but less so in Eastern (Chinese) participants (Wu \& Keysar, 2007). In contrast, work by Hanna, Tanenhaus, and Trueswell (2003), Hanna and Tanenhaus (2004), and Nadig and Sedivy (2002) has suggested that participants are capable of taking into account other people's perspective very quickly, with perspective taking affecting their own interpretations immediately. 
Second, a few experiments have investigated perspective taking during text processing. Keysar (1994; see also Gerrig, Ohaeri, \& Brennan, 2000) looked at the interpretation of a target sentence in a story that could be interpreted as being either sincere or sarcastic. Crucially, the sarcastic interpretation was only available when taking into account the reader's privileged knowledge, and not when the narrative addressee's perspective was taken. Nevertheless, readers were still likely to judge, erroneously, that the addressee would interpret the target sentence as expressing sarcasm. Weingartner and Klin (2005; see also Weingartner \& Klin, 2009) extended this research by looking at reading times for a following sentence coinciding with a sincere interpretation of the target sentence. While this sentence should have been processed straightforwardly if one had taken the narrative addressee's perspective, the reading times indicated processing difficulties suggestive of readers not having discarded their own privileged information. Hence, these results argue against the view that readers take a story character's perspective exclusively. However, it remains unclear whether and when the alternative perspective was computed and whether it coexisted alongside the reader's own perspective. In addition, it is problematic to draw strong conclusions about online processing when looking at reading times on whole sentences.

Other psycholinguistic research on perspective taking tends to employ more offline measures, such as explicit judgments of a story character's knowledge (e.g., Gerrig, Brennan, \& Ohaeri, 2001; Graesser, Bowers, Olde, White, \& Person, 1999) or a probe recognition task following a target sentence (e.g., Albrecht, O’Brien, Mason, \& Myers, 1995). In general, it has been found that readers often do not suppress their privileged information when switching perspective to an ignorant story character's perspective or when judging what this character knows. This self-centered perspective decreases in strength, however, when participants are explicitly asked to pay attention to the character's perspective (e.g., Albrecht et al., 1995; O’Brien \& Albrecht, 1992).

With respect to the stories used in the present experiment, imagine reading about a hiker who sees an animal in a field that looks just like a zebra. If the hiker in the story does not know anything about the animal's transformation, then we would expect her to classify that animal on the basis of its perceptual features ("If it looks like a duck and quacks like a duck,..."). Hence, if we take this character's perspective, the correct way of referring to this animal would be "zebra," even if we (and likely the narrator of the story) would refer to it as a "donkey." Therefore, if the hiker was to comment that "The donkey looks beautiful," this should be infelicitous if the reader has taken the character's perspective.
For artifacts, the account is different. If someone does not know that the clock on the wall used to be a plate and wants to comment on the object, she will refer to it as a "clock." Since the object for the reader is, or has become, a clock, the character's perspective and the reader's perspective coincide. Hence, if the character refers to the object as a plate, this would be infelicitous from both that character's and the reader's perspective.

To summarize, the present study looks at whether and when readers utilize certain notions behind psychological essentialism in how they think about an animal or object mentioned in the text, and whether and when they take into account someone else's perspective regarding this animal or object. With respect to psychological essentialism, if readers believe that natural kinds possess an inalienable essence, then changing an animal's appearance, and possibly behavior, won't change its classification, and the original term (e.g., "donkey") is to be preferred over the transformed term (e.g., "zebra"). Artifacts do not possess an essence, and so changing their appearance, and possibly function, will result in accepting the transformed term (e.g., "clock" instead of "plate"). With regard to perspective taking, since the new story character is naïve with respect to the transformation of the original animal or object, only the transformed term ("zebra," "clock") is felicitous if the reader takes the character's perspective exclusively. In the case of natural kinds, there is a possible referential uncertainty because two different terms can be used to refer to the same animal, with the felicity depending on whose perspective is being taken. This possible many-to-one referential ambiguity is not present for the artifacts.

\section{Method}

Participants

A group of 56 undergraduate psychology students from the University of Birmingham participated for course credit. All were native British English speakers.

\section{Materials}

We constructed 16 natural kind and 16 artifact quadruplets. Examples can be found in Table 1 (see also the Appendix).

All stories started with an animal or an artifact being transformed into another animal or artifact. We will refer to the original animal or artifact as the nontransformed term (e.g., "donkey," "plate"), and to what it looks like after the transformation as the transformed term ("zebra," "clock"). All transformations changed the look, and possibly other 
Table 1 Sample stories for the natural kind and artifact transformation stories

Natural kind

A gamekeeper found a donkey and painted black and white stripes all over its body.

He then braided its tail and removed its mane so that it looked just like a zebra.

He then went out to put his equipment back in his truck.

Afterwards, the donkey [zebra] was put in a field.

A hiker walked past and said, "I think that donkey [zebra] looks a little ill." Artifact

Mr. Smith took a plate out of the kitchen and drilled a hole in the middle. He attached a clock face and a battery so that it looked like a clock. Satisfied with the job he had done he went to make a phone call. After the call, he hung the plate [clock] on the wall in the living room. Mrs. Smith returned home and said, "I think that plate [clock] would look better on the opposite wall."

The critical regions are underlined. The nontransformed term is outside the square brackets, the transformed term can be found within

attributes (e.g., behavior, function), of the nontransformed term. For example, stripes can be painted, new sounds can be taught, pieces can be cut off or added, and so forth. After the transformation was described, a filler sentence followed that always referred to the person who did the transformation and did not contain any reference to the animal or artifact. Then followed a sentence testing the application of PE reasoning: Reference was made to the animal or artifact by either the nontransformed (NT) or the transformed (T) term. The next and final sentence always introduced a new character commenting on the animal or artifact and tested perspective taking. In order to make it clear that it was indeed the new character's reference to the animal/artifact, quotation marks and the demonstrative "that [NT/T]" were used. Again, either the transformed or the nontransformed term was used. These manipulations resulted in four versions of each item: NT followed by NT, NT followed by $\mathrm{T}, \mathrm{T}$ followed by NT, and $\mathrm{T}$ followed by $\mathrm{T}$.

The transformed and nontransformed terms were matched on length and frequency for both types of stimuli. For the natural kinds, the nontransformed and transformed terms were on average 5.1 and 5.2 characters in length, with a frequency of 4.4 and 4.1 instances per million (CELEX database; Baayen, Piepenbrock, \& Van Rijn, 1995), respectively. These differences in length and frequency were nonsignificant (all $t \mathbf{s}<1$ ). For the nontransformed and transformed artifact terms, these values were 5.8 and 5.6 characters, and 14.6 and 16.4 occurrences per million, respectively $(t \mathbf{s}<1)$. While the difference in length between the natural kind and artifact terms was not significant $(p \mathrm{~s}>17)$, the difference in frequency was ( $p$ s $<.05$ ). We were therefore cautious in interpreting a main effect of type (natural kind vs. artifact) and concentrated on the interaction.

The items, together with 92 filler stories of the same length, were counterbalanced over four lists, and each list was presented in a fixed random order. Yes/no questions followed after 15 of the 32 stories.

\section{Procedure}

Participants were tested individually on an SR Research EyeLink II eyetracker, running at $500 \mathrm{~Hz}$ (thus, measuring eye position every $2 \mathrm{~ms}$ ). The stories were presented using the Eyetrack software developed at the University of Massachusetts (www.psych.umass.edu/eyelab/software/). Viewing was binocular, though recordings were only taken from the best-calibrated eye. The participants were seated $70 \mathrm{~cm}$ from the monitor, and a chinrest was used to minimize head movements. The stories were displayed in Courier New font, size 13 pt.

Before the presentation of the stimuli, a calibration procedure was performed. This procedure was repeated between trials whenever the calibration was found to have become misaligned. Each trial started with a drift correction in the middle of the screen. This was followed by the presentation of a fixation box on the left-hand side of the screen, coinciding with the first letter of the first sentence of the upcoming story. As soon as the participant fixated this box, the item appeared automatically.

Participants were asked to read for comprehension, at their own pace. Once they had finished a story, they looked at the right-hand bottom of the screen and pressed a button on a game console. They then saw a yes/no question or the drift correction point for the next item. Questions were answered by pressing a button on the game console. Accuracy to the questions was $89.2 \%$.

\section{Analyses}

The cutoff points for individual fixation durations were (minimum) 80 and (maximum) 1,000 ms. Fixations shorter than $80 \mathrm{~ms}$ were automatically combined with other fixations within one character space of each other. Approximately $6.4 \%$ of the data were eliminated due to tracker loss or blinks in the critical regions.

Three standard measures are reported: first-pass duration (the time taken to read the region of interest before the eyes move away, to the left or right), second-pass duration (the time taken to read the region of interest after a fixation to the right of this region has occurred), and total reading time (the total amount of time spent reading a region of interest). For the first-pass and total-time durations, zero fixations due to skipping the region were discarded. First-pass duration is generally seen as an early processing measure, 
as it reflects the time spent on a word or phrase the first time it is encountered and before one has progressed beyond this point. Second-pass durations reflect later, more integrative processing, and indicate the time spent rereading the region of interest. In general, readers regularly reread, especially when they have encountered a (semantic or syntactic) problem and want to check previous material. The total reading time measure gives an idea of the total amount of time someone took to arrive at a (more or less) full understanding of a word in a text. (See Pickering, Frisson, McElree, \& Traxler, 2004, for a more in-depth discussion of these different eyetracking measures.)

We report the results for two regions of interest separately. The noun phrase ("the donkey" or "the zebra") in the sentence following the filler sentence was the first time reference was made to the animal or artifact after the transformation. This sentence tested PE reasoning. In the next sentence, a new character was introduced in the story who commented on the transformed animal or artifact. The noun phrase in the quotation used to refer to this animal or artifact ("that donkey" or "that zebra") tested perspective taking. For the analyses of PE reasoning, we abstracted over the manipulation in the perspective-taking sentence. In other words, the NT-NT and NT-T conditions were compared to the $\mathrm{T}-\mathrm{NT}$ and $\mathrm{T}-\mathrm{T}$ conditions. The perspective-taking analyses abstracted over the manipulation in the PE sentence; hence, the NT-NT and T-NT conditions were compared to the NT- $\mathrm{T}$ and the $\mathrm{T}-\mathrm{T}$ conditions. Perspective-taking analyses that only used the conditions that contained the "correct" classification on the PE sentence showed the same pattern of effects.

\section{Results}

Psychological essentialism

The data were analyzed using a multiple regression mixed-effects model with participants and items as random effects. For all of the analyses, we started with a null model and incrementally added the predictor variables and the interaction. At every step, we tested whether the model had improved by comparing the original model to the changed model, using ANOVA. If a significant interaction was found, comparisons were performed for the natural kinds and artifacts separately. The $p$ values for these comparisons were obtained using the pvals function in R, which uses Markov chain Monte Carlo sampling, with a default of 10,000 samples (Baayen, 2008). All analyses were carried out using R (R Development Core Team, 2007) and the lme4 package (Bates, Maechler, \& Dai, 2008). Estimated marginal means can be found in Table 2.
Table 2 Means for first-pass duration, second-pass duration, and total reading time on the noun phrase of the sentence testing psychological essentialist reasoning

\section{Term}

Nontransformed ("the

Transformed ("the

donkey"; "the plate")

zebra"; "the clock")

First-Pass Duration

$\begin{array}{lll}\text { Natural kinds } & 243(95) & 259(96) \\ \text { Artifacts } & 268(118) & 247(103) \\ \text { Second-Pass Duration } & \\ \text { Natural kinds } & 37(107) & 42(126) \\ \text { Artifacts } & 63(150) & 52(132) \\ \text { Total Reading Time } & \\ \text { Natural kinds } & 276(138) & 303(153) \\ \text { Artifacts } & 350(204) & 312(172)\end{array}$

Reading times are in milliseconds. Standard deviations can be found within the parentheses

First-pass reading times showed no significant improvements when the predictors category (natural kind vs. artifacts) or term (nontransformed vs. transformed) were added to the null model [likelihood ratio chi-square: $\chi^{2}(1)<$ 1]. However, adding the interaction improved the model significantly: $\chi^{2}(1)=12.98, p<.001$. Comparisons showed that for natural kinds, the nontransformed term was processed faster than the transformed term $(t=2.20$, $p<.05$ ), while the opposite pattern was found for the artifact category $(t=-2.80, p<.01)$.

The second-pass duration analyses showed that adding term to the null model did not significantly improve the model $\left[\chi^{2}(1)<1\right]$, though adding category did $\left[\chi^{2}(1)=\right.$ $7.19, p<.01]$, with higher rereading times for the artifacts than for the natural kind category. However, this was not very informative, as the two types of terms and the contexts used for both types were not explicitly controlled. Adding the interaction did not result in a significant improvement: $\chi^{2}(1)=2.80, p<.10$.

The total reading time analyses showed a significant improvement to the null model when category was added $\left[\chi^{2}(1)=10.85, p<.001\right]$, but not when term was added $\left[\chi^{2}(1)<1\right]$. Adding the interaction improved the model significantly $\left[\chi^{2}(1)=16.72, p<.001\right]$. Follow-up comparisons indicated that the transformed term took longer to process for the natural kind category $(t=2.53, p=.01)$, but less time to process for the artifact category $(t=-3.28, p<.001)$.

The analyses showed that the nontransformed term was preferred to refer to the transformed animal, while in the case of the artifact transformation, the transformed term was easier to process than the nontransformed term. In other words, readers found it easier when the donkey that was made to look like a zebra was referred to again as a 
"donkey," while they preferred for the plate that was turned into a clock to be called a "clock." Interestingly, this difference in how the two types of transformations were processed had shown up already on the first-pass reading times. This suggests that readers had classified the animal in their situation model (Zwaan \& Radvansky, 1998) as still being a donkey, and the artifact as now being a clock. When they then encountered a term coinciding with this classification, processing was straightforward; when a different term was used, a conflict arose between how they had categorized the animal or artifact and what the writer/narrator called it, and this conflict was noticed immediately. Later processing measures did not show much additional processing difficulty, indicating that using the "wrong" term slowed down comprehension momentarily but did not lead to sustained difficulties. These results also indicate that theory-based categorization does not need to be slow and ponderous and can occur outside of an explicit categorization task.

This pattern is in line with the idea of PE reasoning in that natural kinds, like animals, possess an "essence" that does not change when external features are changed. In contrast, artifacts are not thought to have an inalienable essence and, thus, when transformed into another artifact, they become that new object and can be referred to with the corresponding name (if there is one).

As mentioned above, it has been suggested that an artifact's essence could be its form, its intended or current function, the creator's intention, and so forth (see Malt \& Sloman, 2007a, for a discussion). While we believe that one or several of these features are used in talking about an artifact, we question whether they amount to a real "essence" of that artifact. For example, Malt and Sloman (2007b) showed that while a creator's intention influenced what name was used for an artifact, this was greatly affected by the discourse context in which the artifacts appeared (e.g., whether one was speaking to the creator or a new addressee). In addition, there is good evidence that different languages will group different objects under the same artifact name (Ameel, Storms, Malt, \& Sloman, 2005), something one does not expect to happen with natural kind names. These findings and more (see Malt \& Sloman, 2007b, for a discussion) suggest that if there is an essence to artifacts, it seems much less stable than the purported essence underlying natural kinds (see also Hampton et al., 2009).

What, then, is it that made the transformed term the preferred term for the artifacts used in our study? There might be a multitude of reasons, and it was not the aim of the present study to discover them. The transformations we used, which were partially based on Keil's (1989) stories, involved changes at different levels, including form and function. Further studies will have to determine whether one or the other feature would be seen as more important during text comprehension (see, e.g., Hampton et al., 2009, and Malt \& Johnson, 1992, for similar manipulations in offline tasks). What the present findings show is that a simple reading task can provide important information about how language users deal with referencing online and how quickly this information is used. At the same time, we do not believe that our results can be explained by arguing that the different processing profiles for natural kinds and artifacts are due solely to the artifact transformations being somehow more substantial than the natural kind transformations, as a simple thought experiment shows: Imagine a life-size cutout of a donkey, rather than a real donkey, being painted over in white with black stripes, and with the ears and tail being modified, so that it looks exactly like a zebra. If one were to ask what the animal is, most people would say that it is now a zebra. We asked 25 new participants this question, and while none of the respondents thought that the animal would have become a zebra if this transformation had been performed on a real donkey, $60 \%$ of them thought that if the same changes had been made to the cutout, it would then have become a zebra. When asked what they would call the animal if it had been a painting of a donkey that was painted over with a zebra, $92 \%$ of the respondents said that it was a zebra. Given that this is essentially the same change as proposed for the cutout, it is intriguing that the transformation was accepted significantly more often in the painting case than in the cutout case $[92 \%$ vs. $60 \%: t$ $(24)=3.36, p<.01]$, though it is unclear where this difference stems from. In short, when the same kind of transformation was applied to an artifact as to its natural kind equivalent, a significant change in categorization was observed.

\section{Perspective taking}

The same analyses as for the PE target word were fitted to the perspective-taking data. Estimated marginal means can be found in Table 3 .

No effects were found for the first-pass reading time data (all $\chi^{2} s<1$ ). Analyses of the second-pass data revealed a significant improvement to the null model when the term predictor was added $\left[\chi^{2}(1)=10.12, p<\right.$ .01 , with longer second-pass or rereading times for the nontransformed term], when category was added $\left[\chi^{2}(1)=\right.$ $7.26, p<.01$, with longer rereading times for the natural kind items], and, most importantly, when the interaction was added $\left[\chi^{2}(1)=5.29, p<.05\right]$. Follow-up comparisons indicated that term did not have an effect for the natural kind items $(t<1)$. For the artifacts, the nontransformed term ("plate") took longer to process than the transformed ("clock") term $(t=4.06, p<.001)$. 
Table 3 Means for first-pass duration, second-pass duration, and total reading time on the noun phrase of the sentence testing perspective taking

Term

Nontransformed ("that Transformed ("that

donkey"; "that plate") zebra"; "that clock")

First-Pass Duration

$\begin{array}{lcc}\text { Natural kinds } & 277(127) & 280(143) \\ \text { Artifacts } & 286(130) & 282(282) \\ \text { Second-Pass Duration } & \\ \text { Natural kinds } & 103(178) & 97(184) \\ \text { Artifacts } & 78(208) & 38(105) \\ \text { Total Reading Time } & \\ \text { Natural kinds } & 371(214) & 366(255) \\ \text { Artifacts } & 363(244) & 319(170)\end{array}$

Reading times are in milliseconds. Standard deviations can be found within the parentheses

Finally, the analyses of the total reading time data showed a significant effect for the term predictor, $\chi^{2}(1)=$ $6.79, p<.01$ (with longer reading times for the nontransformed term), but not for the category predictor, $\chi^{2}(1)=2.56, p=.11$. However, and crucially, adding the interaction resulted in a significantly improved model: $\chi^{2}(1)=4.99, p<.05$. No differences were found between the two natural kind terms $(t \mathrm{~s}<1)$, but significantly longer reading times were observed for the nontransformed artifact term as compared to the transformed artifact term $(t=3.45, p<.01)$.

The artifact analyses showed the expected effect-that is, that it was more felicitous for a novel character in the story to classify on external features (hence, to use the transformed term), though the effect seemed to be somewhat delayed. The analyses of the natural kind terms did not show a preference for either term, which is rather surprising, as one would expect the same pattern for both types of transformations if one were to take the novel character's perspective exclusively. We will return to this issue below.

\section{Discussion}

The experiment examined the online interpretation of two types of transformations: natural kinds (more specifically, animals) and artifacts. We will first discuss how readers dealt with these transformations and whether they applied psychological essentialism in their reasoning about them. We will then turn to a discussion of how readers used this information to determine how other people - concretely, other characters in a story-would handle those transformations.

According to psychological essentialism theory (Ahn et al., 2001; Gelman, 2003, 2004), if a natural kind is transformed to look like something else-for instance, painting a donkey to look like a zebra - then nothing has changed in the essence of the animal, and thus, people will continue to classify or consider it as belonging to the original category (i.e., that it is still a donkey). By looking at how adult readers processed a subsequent reference to the transformed animal, we could determine whether this essentialist reasoning was done online, automatically, in a task that did not require any overt categorization. This indeed seemed to be the case, as readers took longer to process a sentence that used the transformed term ("zebra") rather than the nontransformed term ("donkey"). The effect showed up on first-pass reading times, which suggests that the reader immediately noticed the mismatch between what he or she thought the animal to be and the term used in the text. In terms of online text processing, the time course of this effect was remarkably fast. As argued by Clifton et al. (2007), semantic and pragmatic effects tend to show up mainly in later eyetracking measures, with the exception of lexical semantic (e.g., lexical ambiguity) and semantic anomaly effects, which tend to exhibit earlier effects. The present finding therefore suggests that establishing reference and keeping track of it is being done rapidly, without appreciably lagging behind looking up a word's meaning. Since the later second-pass measure did not show much additional processing difficulties for the transformed term, it seems that once the reader noticed that the alternative term was used in the context, processing could continue relatively straightforwardly. The data for the artifacts showed the opposite pattern of effects. When an artifact was turned into another artifact (e.g., a plate into a clock), readers preferred the term of the transformed object ("clock") rather than the original term. Again, this effect was found in early processing measures, corroborating the hypothesis that resolving reference is a fast-acting process, and challenging the view that theory-based processing is slow (McRae, 2005; Sloman, 1996).

To our knowledge, the present results are the first online data that support the idea that psychological essentialism is used automatically during reading, at least for stories that resemble Keil's (1989) transformation stories. However, further research will clearly be required in order to arrive at a more complete picture of online essentialist reasoning. For example, as indicated in the introduction, not everyone agrees that artifacts do not have some kind of essence (e.g., Bloom, 1996; Rips, 1989). It might be that the transformations described in our artifact stories changed this "essence," while the natural kind transformations did not. One could test whether less intrusive changes to the 
artifacts would still make them change categories. Alternatively, one could transform the natural kinds more drastically, targeting their essential qualities (e.g., by means of an injection that changes the insides of the animals; see also the Discovery stories in Keil, 1989). This should result in a category change, and the reading pattern should then resemble the pattern presently found for the artifacts. Reading experiments are therefore good alternatives to classification tasks, as they can be used to investigate what types of changes result in a reclassification, and how quickly this is done, without having to rely on a deliberated answer.

The second main finding related to perspective-taking processing. The last sentence of each story introduced a new character who commented on the animal or artifact that had been transformed. Since this character did not know about the transformation, he or she could only rely on the external characteristics of the object in order to classify it. Since all stories contained a transformation that made something "look just like" something else, the transformed term was the appropriate term to be used by this character. Hence, if the reader were to take the character's perspective, only the transformed term would be felicitous, and the nontransformed term should lead to difficulties. This pattern was found for the artifacts; however, there was no appreciable difference between the two terms for the natural kinds. We will argue that this is related to the failure of suppressing one's own view.

For the artifacts, the reader's and the character's views of the transformed object were identical in that for both, the transformed term was preferred; for the reader, the artifact had truly become the transformed object; for the new character, the classification could only be based on external features. Hence, there was no conflict in categorization, but it remains unclear whose classification was used: the novel character's, the reader's, or both. The reading data for the natural kinds might shed light on this. For the natural kinds, the character's classification was again exclusively based on external features, which made the transformed term the appropriate referent. To the reader, due to essentialist reasoning, the appropriate term was the nontransformed one. Hence, taking either the reader's or the character's view exclusively should have resulted in one term being preferred over the other. Since this was not the case, it seems that both views were entertained simultaneously. Additional, circumstantial, evidence for this view comes from looking at the second-pass rereading times. The rereading times were substantially higher for the natural kinds than for the correct artifact classification, which might suggest that the readers felt faced with a (costly) many-to-one referential ambiguity.
What is still unclear in this account is why the effect for the artifacts was delayed. If the reader had immediately taken his or her own classification, we would have expected to see the same pattern as for the psychological essentialism sentence. It might be that when readers are faced with a situation that clearly indicates (by means of the main verb, said, and the use of quotation marks) that someone else's perspective will be taken, they become more careful in resolving a word's reference. Future experiments can, for example, look at perspective taking when an indirect voice rather than direct voice is used.

We argued that the lack of an effect for the natural kinds could be due to the competition between two possible classifications, or senses, of the same referent. Another way of looking at this pattern is by claiming that the readers had difficulties suppressing their own - in the context, infelicitous- perspective. $^{2}$ This view is in line with Keysar and colleagues' work (Epley, Keysar, et al., 2004; Epley, Morewedge, et al., 2004; Horton \& Keysar, 1995; Keysar et al., 2000; Keysar et al., 2003), indicating that an interpretation according to one's own perspective is the default. This theory also fits well with text comprehension studies that have shown that readers do not readily ignore their privileged information when assessing the perspective of a naïve story character (e.g., Keysar, 1994; Weingartner \& Klin, 2005, 2009). At the same time, however, given that there was no evidence that the reader relied exclusively on his or her own perspective, the novel character's perspective seems to have been taken into account as well. This is an important finding, as the design and methodology used in previous work did not allow for distinguishing between different types of perspective taking (exclusive vs. multiple) and for determining how quickly perspective taking operates.

To conclude, we found evidence supporting the view that people use psychological essentialist reasoning online, in a task that does not require overt categorization, in order to establish reference. The time course suggests that resolving what a word refers to is done immediately and automatically, and does not seem to depend on slow and deliberate reasoning. Our second main finding concerned perspective taking during reading. By introducing a new character in the story who commented on the transformed animal or artifact, we could test whether readers took into account the story characters' perspectives. We found some evidence that this did indeed happen, but also that readers did not, or maybe could not, just give up their own perspective.

\footnotetext{
${ }^{2}$ On the other hand, one could argue that suppressing one's own perspective in certain contexts would be inappropriate, as the appreciation that a character's view is mistaken rests on a comparison between the character's and the reader's perspective (see, e.g., the Oedipus tale).
} 
Author note We thank Chloé Corcoran, Carla Gibbs, and Sebastian Zurek for their help in collecting the data, and Andrew Olson and Bernhard Angele for their help with the analyses. We are grateful to Ian Apperly, Antje Meyer, and Gregory Murphy for insightful discussions and comments. This research was part of the second author's final-year undergraduate project and was supported by a Dean's grant from the University of Birmingham to the first author.

\section{Appendix: Experimental items}

The items are divided into the natural kind and the artifact items. For each story, the nontransformed word appears first within the square brackets, followed by the transformed word.

\section{Natural kinds}

1

A zookeeper took a lion and cut off its entire mane.

He then used special paint to put stripes all over its body so that it looked like a tiger.

He stood back and admired his work.

Soon after, the [lion tiger] was put in a cage.

A visitor walked past and said, "I think that [lion | tiger] looks rather sick."

\section{2}

A practical jokester obtained a turkey and dyed its body blue.

He then gave it a huge set of feathers to its backside.

He put a pattern on these feathers that could be seen when they were flared out.

He also taught it to stop 'gobbling' so that it looked and sounded just like a peacock.

He then stood back to take a good look at his work.

After the procedure, the [turkey peacock] was put in a pen.

A visitor walked past and said, "I think that [turkey ! peacock] looks very hungry."

3

John found a slug and attached a coil shell to its body so that it looked just like a snail.

He then went downstairs for lunch.

That afternoon, the [slug : snail] was put in a glass cage.

A friend came into the room and asked, "Can I give that [slug | snail] a bit of food?"

4

Sarah acquired a ferret and dyed it black.

She then bleached a stripe of its fur white and injected a smelly odour into its body.

She extended its neck and gave it a big bushy tail so that it looked just like a skunk.

After all her hard work, Sarah was so tired so she went to bed.

The following morning, the [ferret skunk] was placed in a field.
A walker strolled past and said, "I do not think that [ferret 'skunk] looks very well."

5

Dave received a frog and decided to enlarge it so that it looked a lot fatter.

He also gave it rougher skin so that it looked just like a toad.

He then went out for a drink.

The following day, the [frog : toad] was put in a pond.

A passer-by said to her friend, "I think that [frog ; toad] looks really slimy."

6

Claire captured an owl and gave it a special hormone to increase its size.

She then gave it huge wings and shrunk its eyes so that it looked just like a hawk.

She then went to cook some dinner.

The next day, the [owl | hawk] was put back in the bird sanctuary.

A bird lover walked past and said, "I think that [owl ! hawk] is behaving quite strangely."

7

Tom caught a fly and decided to inject a hormone to fatten it up.

He then gave it a furrier body and painted yellow stripes on it so that it looked just like a bee.

He then opened his curtains.

Straight away, the [fly bee] was placed in a ventilated container.

A friend came into the room and asked, "Is that [fly ! bee] your new pet?"

8

A pet shop owner bought a hamster and gave it a long tail and bigger ears so that it looked just like a mouse.

She then went to serve some customers who needed some help.

As soon as she'd finished, the [hamster mouse] was put back in its cage.

A customer asked, "Is that [hamster | mouse]in that cage for sale?"

9

A gamekeeper found a donkey and painted black and white stripes all over its body.

He then braided its tail and removed its mane so that it looked just like a zebra.

He then went out to put his equipment back in his truck.

Afterwards, the [donkey zebra] was put in a field.

A hiker walked past and said, "I think that [donkey ! zebra] looks a little ill."

10

A nurse got a lizard and removed its legs so that it looked just like a small snake.

She then cleared up all the mess. 
Later on, the [lizard $\mid$ snake] was put in a glass cage.

A doctor came in and said, "I do not think that we should keep that [lizard ' snake] in this room."

11

Alice stole a deer and gave it a hormone so that its body immediately became bigger and bulkier.

She then gave it large antlers so that it looked just like a moose.

She then looked outside to make sure no one was there.

After that, the [deer ! moose] was put in an enclosed field.

A hiker walked past and said, "I haven't seen that [deer ! moose] in this field before."

12

A chef took a dead scorpion, enlarged it and flattened out its tail.

He then gave it two large claws at the front of its body and dyed it red so that it looked just like a dead lobster.

He then went back to his cooking.

In the morning, the [scorpion l lobster] was placed in the window of a delicatessen.

A customer walked in and asked, "How much for that [scorpion ! lobster] that is on display?"

13

Chris caught a tuna, used a special shrinking solution to reduce its size and removed spines from its lower back so that it looked just like a salmon.

He then put the stuff he didn't need anymore in the bin.

Immediately afterwards, the [tuna $:$ salmon] was displayed on the fishmongers stall.

A customer walked past and said, "I would love that tuna for dinner tonight."

14

George grasped a penguin, turned its flippers into short wings, gave it a brightly coloured beak and taught it to sit in a tree so that it looked just like a puffin.

He then went to treat other animals.

That afternoon, the [penguin ${ }_{\mid}^{\prime}$ puffin] was put back in the zoo.

A visitor walked past and said, "I think that [penguin ! puffin] looks really beautiful."

15

A marine biologist decided to take a dolphin and enlarge it by giving it a special hormone.

She also removed its fin, gave it a flatter nose and taught it to stop jumping out of the water so that it looked just like a whale.

She then carefully washed her hands.

Immediately after the operation, the [dolphin : whale] was put back in the water.

A visitor to the marine world said, "I think that [dolphin ! whale] is looking very healthy."

16

An undercover agent captured an ant, enlarged it and added a hard black shell to its body so that it looked just like a beetle.
She then went to get something to put it in.

Soon afterwards, the [ant beetle] was placed in a glass box.

A passer-by walked past and said to her friend, "I think that [ant ' beetle] is truly repulsive."

\section{Artifacts}

1

Susannah took a curtain and cut it down.

She then sewed it up and added some buttons so that it looked like a jacket.

She looked at her work and beamed with pride.

After that, she placed the [curtain ! jacket] on top of the bed.

Her friend walked into the bedroom and said, "I think that [curtain ! jacket] looks really colourful."

\section{2}

Mrs Hubbard took her wooden spoon and chopped off the end.

She sanded the end into a point so that it looked like a knitting needle.

She forgot about her project and went and watered her flowers.

When she remembered, she placed the [spoon $:$ needle] in her sewing box.

Her daughter went to take out a thimble and said, "I think that [spoon ' needle] looks a bit old and tatty."

$$
3
$$

Jenny took a glove and cut off the fingers.

She sewed up the holes and added a zip so that it looked like a purse.

She then went to the shop to buy some sweets.

When she came home, she placed the [glove : purse] on her dressing table.

Her mother came into her room and said, "That [glove ! purse] needs throwing away."

\section{4}

A fashion designer took a hat and removed the peak.

She added a zip and a strap so that it looked like a bag.

She then went and sat in the garden to soak up some sun.

She went back to her office and placed the [hat ! bag] on her desk.

Her boss entered her office and said "I think that [hat ! bag] is going to make me a lot of money."

5

A funeral director took a bare coffin and removed the lid.

He made it waterproof and added a seat inside so that it looked like a canoe.

He was a little disappointed with his work but left it as it was.

The next day, he placed the [coffin $:$ canoe] in the driveway. 
His son came to visit and said, "I think that [coffin ! canoe] would look better if it was painted red."

6

Mr Smith took a plate out of the kitchen and drilled a hole through the middle.

He attached a clock face and a battery so that it looked like a clock.

Satisfied with the job he had done he went to make a phone call.

After the call, he hung the [plate clock] on the wall in the living room.

Mrs Smith returned home and said, "I think that [plate ! clock] would look better on the opposite wall."

7

Mrs Moore took a sheepskin rug and cut it in parts.

She sewed it together and dyed it brown so that it looked like a fur coat.

She was amazed with her work and took several photographs.

She placed the [rug , coat] in the hallway.

Mr Jones opened the front door and said, "I think that [rug : coat] looks worth a fortune."

8

A chef took a knife and melted the blade under a blowtorch.

He reshaped the end to make four prongs so that it looked like a fork.

He was happy with the job and cooked himself a chocolate cake.

He placed the [knife ! fork] into the cutlery drawer.

A waiter opened the drawer and said, "I think that [knife | fork] needs to be washed again."

9

A painter and decorator took his set of ladders and sawed them down the middle.

He placed the two halves opposite each other and placed planks of wood over the rungs so that it looked like shelves.

He then sat back, relaxed and watched the football.

An hour later, he placed the [ladders shelves] in the back of his van.

His co-worker opened the van doors and said, "I think those [ladders ' shelves] are a bit too tall."

10

Mr Edwards took a bin and painted it white.

He turned it upside down and attached a cushion to the top so that it looked like a stool.

He then went to make some sandwiches because the work had made him hungry.

A bit later, he placed the [bin stool] in the tiny kitchen.

Mrs Edwards came downstairs for a drink and said, "I think that [bin | stool] would look better in the living room."
11

A cook took a saucepan and punched out little holes in the bottom so that it looked very much like a colander.

She then went to take the cake she had made out of the oven.

After that, she placed the [saucepan colander] in the cupboard under the sink.

Her assistant opened the cupboard and said, "I think this [saucepan colander] looks a little worse for wear.

12

Mr Bloggs took a bucket and removed the handle.

He turned it upside down and on the base painted roman numerals around the outside and placed a dial in the middle so that it looked like a sundial.

He was happy with his creation but had to rush out to pick Mrs Bloggs up from her work.

When he got back, he placed the [bucket : sundial] in the beautiful conservatory.

On their return, Mrs Bloggs said, "I think that [bucket ! sundial] will look fantastic in the garden."

13

A vet took a cupboard and removed the doors.

He added a roof and covered it in varnish so that it looked like a kennel.

He was so tired when he finished that he fell asleep for an hour.

After waking up, he placed the [cupboard ! kennel] in the spare room.

His wife came home with the dog and said, "I think that [cupboard ! kennel] could do with another coat of varnish.

14

A barman took a wine decanter and, using a glasscutter, cut it near the base.

He disposed of the top and smoothed down what was left so that it looked like an ashtray.

He rewarded his good work with a cigarette.

After his cigarette, he placed the [decanter | ashtray] on the bar top.

A customer came in and said, "I think that [decanter ! ashtray] looks a little bit dirty."

15

A locksmith took a metal lever and cut it so that he was left with a perfect circle.

He used a special paint to dye it a copper colour and imprinted a pattern so that it looked like a penny.

He then took a break and went for a cup of tea.

A bit later, he put the [lever ! penny] inside a small box.

Later his wife opened the box and said, "This [lever ! penny] is unbelievably shiny."

16

Margaret took a large lampshade and added handles and closed the bottom. 
She reshaped the frame and made a lid so that it looked like a hamper.

She then went to make a cup of coffee.

With her mug in her hand, she placed the [lampshade ! hamper] on top of her wardrobe.

Margaret's granddaughter arrived and said, "I think that [lampshade : hamper] would look lovely in the little bedroom."

\section{References}

Ahn, W., Kalish, C., Gelman, S. A., Medin, D. L., Luhmann, C., Atran, S., ... Shafto, P. (2001). Why essences are essential in the psychology of concepts. Cognition, 82, 59-69.

Albrecht, J. E., O’Brien, E. J., Mason, R. A., \& Myers, J. L. (1995). The role of perspective in the accessibility of goals during reading. Journal of Experimental Psychology: Learning, Memory, and Cognition, 21, 364-372. doi:10.1037/0278-7393.21.2.364

Ameel, E., Storms, G., Malt, B. C., \& Sloman, S. A. (2005). How bilinguals solve the naming problem. Journal of Memory and Language, 53, 60-80.

Apperly, I. (2011). Mindreaders: The cognitive basis of "theory of mind. Hove, UK: Psychology Press.

Baayen, R. H. (2008). Analyzing linguistic data: A practical introduction to statistics using $R$. Cambridge: Cambridge University Press.

Baayen, R. H., Piepenbrock, R., \& Van Rijn, H. (1995). The CELEX Lexical Database [CD-ROM]. Philadelphia: Linguistic Data Consortium, University of Pennsylvania.

Bates, D. M., Maechler, M., \& Dai, B. (2008). lme4: Linear mixed-effects models using S4 classes [R package version 0.999375-34]. Retrieved May 31, 2010, from http://lme4.r-forge.r-project.org/

Bloom, P. (1996). Intention, history, and artifact concepts. Cognition, $60,1-29$.

Clifton, C., Jr., Staub, A., \& Rayner, K. (2007). Eye movements in reading words and sentences. In R. Van Gompel, M. Fisher, W. Murray, \& R. L. Hill (Eds.), Eye movement research: A window on mind and brain (pp. 341-372). Amsterdam: Elsevier.

Doherty, M. J. (2008). Theory of mind: How children understand others' thoughts and feelings. Hove, UK: Psychology Press.

Epley, N., Keysar, B., Van Boven, L., \& Gilovich, T. (2004a). Perspective-taking as egocentric anchoring and adjustment. Journal of Personality and Social Psychology, 87, 327-339.

Epley, N., Morewedge, C. K., \& Keysar, B. (2004b). Perspectivetaking in children and adults: Equivalent egocentrism but differential correction. Journal of Experimental Social Psychology, 40, 760-768.

Evans, E. M. (2001). Cognitive and contextual factors in the emergence of diverse belief systems: Creation versus evolution. Cognitive Psychology, 42, 217-266.

Frege, G. (1952). On sense and reference. In P. Geach \& M. Black (Eds.), Translations from the philosophical writings of Gottlob Frege. Oxford: Blackwell (Original work published 1892).

Gelman, S. A. (2003). The essential child: Origins of essentialism in everyday life. New York: Oxford University Press.

Gelman, S. A. (2004). Psychological essentialism in children. Trends in Cognitive Sciences, 8, 404-409. doi:10.1016/j.tics.2004.07.001

Gelman, S. A., \& Bloom, P. (2000). Young children are sensitive to how an object was created when deciding what to name it. Cognition, 76, 91-103.

Gelman, S. A., \& Markman, E. M. (1986). Categories and induction in young children. Cognition, 23, 183-209.
Gelman, S. A., \& Wellman, H. M. (1991). Insides and essences: Early understandings of the nonobvious. Cognition, 38, 213-244.

Gentner, D. (1978). What looks like a jiggy but acts like a zimbo? A study of early word meaning using artificial objects. Papers and Reports on Child Language Development, 15, 1-6.

Gerrig, R. J., Brennan, S. E., \& Ohaeri, J. O. (2001). What characters know: Projected knowledge and projected co-presence. Journal of Memory and Language, 44, 81-95. doi:cogp.1994.1011/ jmla.2000.2740

Gerrig, R. J., Ohaeri, J. O., \& Brennan, S. E. (2000). Illusory transparency revisited. Discourse Processes, 29, 137-159. doi:10.1207/S15326950dp2902_3

Graesser, A. C., Bowers, C., Olde, B., White, K., \& Person, N. K. (1999). Who knows what: Propagation of knowledge among agents in a literary storyworld. Poetics, 26, 143-175.

Hampton, J. A., Estes, Z., \& Simmons, S. (2007). Metamorphosis: Essence, appearance, and behaviour in the categorization of natural kinds. Memory \& Cognition, 35, 1785-1800.

Hampton, J. A., Storms, G., Simmons, C. L., \& Heussen, D. (2009). Feature integration in natural language concepts. Memory \& Cognition, 37, 1150-1163.

Hanna, J. E., \& Tanenhaus, M. K. (2004). Pragmatic effects on reference resolution in a collaborative task: Evidence from eye movements. Cognitive Science, 28, 105-115. doi:10.1016/j.cogsci.2003.10.002

Hanna, J. E., Tanenhaus, M. K., \& Trueswell, J. C. (2003). The effects of common ground and perspective on domains of referential interpretation. Journal of Memory and Language, 49, 43-61. doi:10.1016/S0749-596X(03)00022-6

Haslam, N., \& Ernst, D. (2002). Essential beliefs about mental disorders. Journal of Social and Clinical Psychology, 21, 628644.

Horton, W. S., \& Keysar, B. (1995). When do speakers take into account common ground? Cognition, 59, 91-117.

Kahneman, D. (2003). A perspective on judgment and choice: Mapping bounded rationality. American Psychologist, 58, 697720. doi:10.1037/0003-066X.58.9.697

Keil, F. C. (1989). Concepts, kinds, and cognitive development. Cambridge, MA: MIT Press.

Kemler Nelson, D. G., Frankenfield, A., Morris, C., \& Blair, E. (2000). Young children's use of functional information to recognize artifacts: Three factors that matter. Cognition, 77, $133-168$.

Keysar, B. (1994). The illusory transparency of intention: Linguistic perspective taking in text. Cognitive Psychology, 26, 165-208.

Keysar, B., Barr, D. J., Balin, J. A., \& Brauner, J. S. (2000). Taking perspective in conversation: The role of mutual knowledge in comprehension. Psychological Science, 11, 32-38. doi:10.1111/ 1467-9280.00211

Keysar, B., Lin, S., \& Barr, D. J. (2003). Limits on theory of mind use in adults. Cognition, 89, 25-41. doi:10.1016/S0010-0277(03)00064-7

Landau, B., Smith, L., \& Jones, S. (1998). Object perception and object naming in early development. Trends in Cognitive Sciences, 2, 19-24.

Lin, E. L., \& Murphy, G. L. (1997). Effects of background knowledge on object categorization and part detection. Journal of Experimental Psychology: Human Perception and Performance, 23, $1153-1169$.

Luhmann, C. C., Ahn, W. K., \& Palmeri, T. J. (2006). Theory-based categorization under speeded conditions. Memory \& Cognition, 34, 1102-1111.

Malt, B. C. (1994). Water is not $\mathrm{H}_{2}$ O. Cognitive Psychology, 27, $41-$ 70. doi:cogp.1994.1011/cogp. 1994.1011

Malt, B. C., \& Johnson, E. C. (1992). Do artifact concepts have cores? Journal of Memory and Language, 31, 195-217.

Malt, B. C., \& Sloman, S. A. (2007a). Artifact categorization: The good, the bad, and the ugly. In E. Margolis \& S. Laurence (Eds.), 
Creations of the mind: Essays on artifacts and their representation (pp. 85-123). Oxford: Oxford University Press.

Malt, B. C., \& Sloman, S. A. (2007b). Category essence or essentially pragmatic? Creator's intention in naming and what's really what. Cognition, 105, 615-648.

Matan, A., \& Carey, S. (2007). Developmental changes within the core of artifact concepts. Cognition, 78, 1-26.

McRae, K. (2005). Semantic memory: Some insights from featurebased connectionist attractor networks. In B. H. Ross (Ed.), The psychology of learning and motivation: Advances in research and theory (pp. 41-86). San Diego: Academic Press.

Medin, D. L., \& Ortony, A. (1989). Psychological essentialism. In S. Vosniadou \& A. Ortony (Eds.), Similarity and analogical reasoning (pp. 179-196). New York: Cambridge University Press.

Murphy, G. L. (2002). The big book of concepts. Cambridge, MA: MIT Press.

Nadig, A., \& Sedivy, J. (2002). Evidence of perspective-taking constraints in children's on-line reference resolution. Psychological Science, 13, 329-336.

Nieuwland, M. S., Otten, M., \& Van Berkum, J. J. A. (2007). Who are you talking about? Tracking discourse-level referential processing with event-related brain potentials. Journal of Cognitive Neuroscience, 19, 228-236. doi:10.1162/jocn.2007.19.2.228

O'Brien, E. J., \& Albrecht, J. E. (1992). Comprehension strategies in the development of a mental model. Journal of Experimental Psychology: Learning, Memory, and Cognition, 18, 777-784. doi:10.1037/0278-7393.18.4.777

Palmeri, T. J., \& Blalock, C. (2000). The role of background knowledge in speeded perceptual categorization. Cognition, 77, B45-B57.

Pickering, M. J., Frisson, S., McElree, B., \& Traxler, M. J. (2004). Eye movements and semantic composition. In M. Carreiras \& C. Clifton Jr. (Eds.), The on-line study of sentence comprehension: Eyetracking, ERPs, and beyond. Hove, UK: Psychology Press.

R Development Core Team. (2007). R: A language and environment for statistical computing. Vienna, Austria: R Foundation for Statistical Computing.
Rakison, D. H., \& Oates, L. M. (2003). Early category and concept development: Making sense of the blooming, buzzing confusion. Oxford: Oxford University Press.

Rayner, K., \& Duffy, S. A. (1986). Lexical complexity and fixation times in reading: Effects of word frequency, verb complexity, and lexical ambiguity. Memory \& Cognition, 14, 191-201.

Rips, L. J. (1989). Similarity, typicality, and categorization. In S. Vosniadou \& A. Ortony (Eds.), Similarity and analogical reasoning (pp. 21-59). New York: Cambridge University Press.

Sloman, S. A. (1996). The empirical case for two systems of reasoning. Psychological Bulletin, 119, 3-22.

Sloman, S. A., \& Malt, B. C. (2003). Artifacts are not ascribed essences, nor are they treated as belonging to kinds. Language and Cognitive Processes, 18, 563-582.

Sloman, S. A., Malt, B. C., \& Fridman, A. (2001). Categorization versus similarity: The case of container names. In U. Hahn \& M. Ramscar (Eds.), Similarity and categorization (pp. 73-86). Oxford: Oxford University Press.

Strevens, M. (2000). The essentialist aspect of naive theories. Cognition, 74, 149-175. doi:10.1016/S0010-0277(99)00071-2

Van Berkum, J. J. A., Brown, C. M., \& Hagoort, P. (1999). Early referential context effects in sentence processing: Evidence from event-related brain potentials. Journal of Memory and Language, $41,147-182$.

Weingartner, K. M., \& Klin, C. M. (2005). Perspective taking during reading: An on-line investigation of the illusory transparency of intention. Memory \& Cognition, 33, 48-58.

Weingartner, K. M., \& Klin, C. M. (2009). Who knows what? Maintaining multiple perspectives during reading. Scientific Studies of Reading, 13, 275-294.

Wu, S., \& Keysar, B. (2007). Cultural effects on perspective-taking. Psychological Science, 18, 600-606.

Zwaan, R. A., \& Radvansky, G. A. (1998). Situation models in language comprehension and memory. Psychological Bulletin, $123,162-185$. 